\title{
Erratum to: The Elements Steering Pathogenesis in IgG-Mediated Alloimmune Diseases
}

\author{
Myrthe E. Sonneveld $^{1}$ • C. Ellen van $\operatorname{der}_{\operatorname{Schoot}^{1}} \cdot$ Gestur Vidarsson $^{1}$
}

Published online: 28 April 2016

(C) Springer Science+Business Media New York 2016

Erratum to: J Clin Immunol (2016)

DOI 10.1007/s10875-016-0253-x

The original version of this article unfortunately contained mistakes in Table 1. It shows 1 arrow pointing down to the left of "Affinity FcyRIIIB" instead of 2 arrows pointing up. Also, some question marks are missing.

In addition, the authors would like to amend the term "Fucosylation" under the header "Glycosylation" to "Afucosylation". The correct version is presented below.

Table 1 Effect of Fcglycosylation of human IgG to binding affinitiets to human Fc $\gamma \mathrm{R}$

\begin{tabular}{ll}
\hline Glycosylation & Functional effect \\
\hline Bisecting GlcNAc & Unknown \\
Galactosylation & $\uparrow$ Affinity Fc $\gamma$ R? \\
& Affinity C1q? \\
& $\uparrow$ Dectin1 association with Fc $\gamma$ RIIb? \\
& $\downarrow$ Affinity Fc $\gamma$ R? \\
Sialylation & $\downarrow$ Affinity C1q \\
& $\uparrow$ DC-SIGN? \\
& $\uparrow \uparrow$ Affinity Fc $\gamma$ RIIIa \\
Afucosylation & $\uparrow \uparrow A f f i n i t y ~ F c \gamma R I I I b$ \\
& Other Fc $\gamma R$ ? \\
\hline
\end{tabular}

The online version of the original article can be found at doi:10.1007/ s10875-016-0253-x.

Gestur Vidarsson

G.Vidarsson@sanquin.nl

1 Department of Experimental Immunohematology, Sanquin Research, Amsterdam and Landsteiner Laboratory, Academic Medical Center, University of Amsterdam, Plesmanlaan 125, 1066 CX Amsterdam, The Netherlands 